Check for updates

Cite this: RSC Adv., 2020, 10, 1666

Received 23rd November 2019 Accepted 23rd December 2019

DOI: 10.1039/c9ra09821f

rsc.li/rsc-advances

\section{Dealloyed porous gold anchored by in situ generated graphene sheets as high activity catalyst for methanol electro-oxidation reaction $\uparrow$}

\author{
Hui Xu, (D)*ab Shuai Liu, (D) ${ }^{\text {b }}$ Xiaoliang Pu, ${ }^{\text {b }}$ Kechang Shen, ${ }^{c}$ Laichang Zhang, ${ }^{d}$ \\ Xiaoguang Wang, (D) Jingyu Qin ${ }^{b}$ and Weimin Wang (D) *b
}

\begin{abstract}
A novel one-step method to prepare the nanocomposites of reduced graphene oxide (RGO)/nanoporous gold (NPG) is realized by chemically dealloying an $\mathrm{Al}_{2} \mathrm{Au}$ precursor. The $\mathrm{RGO}$ nanosheets anchored on the surface of NPG have a cicada wing like shape and act as both conductive agent and buffer layer to improve the catalytic ability of NPG for methanol electro-oxidation reaction (MOR). This improvement can also be ascribed to the microstructure change of NPG in dealloying with RGO. This work inspires a facile and economic method to prepare the NPG based catalyst for MOR.
\end{abstract}

\section{Introduction}

Traditionally gold has not been considered as a useful catalyst due to its chemical inertness. However, recent studies have found that when the feature size decreases to the nanometer scale, the nanostructured gold can exhibit unusual catalytic properties in several important reactions such as energy generation, environment protection and biosensing..$^{1-6}$ Much effort has been devoted to develop novel nanostructured gold with various morphologies to exploit the innovative nanoscale chemical effects. ${ }^{7,8}$ Nanoporous gold (NPG) with high surface area can be fabricated by selectively etching an alloy, i.e., dealloying, and the as-evolved bi-continuous open ligament/ channel structure enables fast transport of medium molecules and electrons, which is particularly beneficial for electrocatalysis. $^{9-11}$ Over the past decade, methanol electro-oxidation reaction (MOR) has been receiving great attentions due to its importance in direct methanol fuel cells (DMFCs). ${ }^{\mathbf{1 2 - 1 4}}$ Generally, the surface of Pt or Pt based catalysts is easy to be poisoned by the intermediate species formed in MOR, which further

${ }^{a}$ State Key Laboratory for Modification of Chemical Fibers and Polymer Materials, International Joint Laboratory for Advanced Fiber and Low-dimension Materials, College of Materials Science and Engineering, Donghua University, Shanghai 201620, China. E-mail: xuhui199278@dhu.edu.cn

${ }^{b}$ Key Laboratory for Liquid-Solid Structural Evolution and Processing of Materials, Ministry of Education, Shandong University, Jinan 250061, China. E-mail: weiminw@sdu.edu.cn

'Ulsan Ship and Ocean College, Ludong University, Yantai 264025, China

${ }^{a}$ School of Engineering, Edith Cowan University, 270 Joondalup Drive, Joondalup, Perth, WA6027, Australia

${ }^{e}$ Laboratory of Adv. Mater. \& Energy Electrochemistry, Taiyuan University of Technology, Taiyuan 030024, China

$\dagger$ Electronic supplementary information (ESI) available. See DOI: $10.1039 / \mathrm{c} 9 \mathrm{ra0} 9821 \mathrm{f}$ declines the catalytic activity. ${ }^{15,16}$ Surprisingly, the unique oxidation mechanism of MOR on NPG electrode protects it free from poisoning. ${ }^{12,17-20}$ And the specific reaction steps are described in discussion parts.

The excellent catalytic performance of NPG mainly depends on the uniform and small nanopore size. ${ }^{21}$ Several reports have proved that by adjusting the precursor alloy component, ${ }^{22-24}$ dealloying time ${ }^{25}$ dealloying temperatures, ${ }^{26}$ and etching solutions, ${ }^{27-29}$ the pore size of nanoporous gold can be tuned. Bäumer et $a l .{ }^{30}$ have found that surface Ag impurities are crucial for the remarkable oxidative activity of NPG. Our previous report noted that NPG with a three-dimensional (3D) bicontinuous interpenetrating ligament-channel structure can be prepared by dealloying the melt spun $\mathrm{Al}_{2} \mathrm{Au}$ ribbon precursors with different circumferential speeds $\left(S_{\mathrm{c}}\right) \cdot{ }^{31}$ We also can further enhance the catalytic activity for MOR by adjusting magnetic field in dealloying. ${ }^{32}$

Recently, given its large specific surface area, ${ }^{33}$ unique electronic properties, ${ }^{34-37}$ and excellent mechanical strength and flexibility, ${ }^{38-40}$ graphene, ${ }^{41}$ a flat monolayer of carbon atoms densely packed into a $2 \mathrm{D}$ honeycomb lattice, is a promising support to disperse catalytically active metal nanoparticles. ${ }^{\mathbf{4 2 - 4 4}}$ Several monometallic nanoparticles, such as $\mathrm{Pd},{ }^{45} \mathrm{Pt},{ }^{46} \mathrm{Au},{ }^{47}$ and $\mathrm{Ag}^{48}$ have been successfully dispersed on graphene, and the hybrids exhibit an impressive catalytic performance in various reactions. A strong metal-graphene interaction was revealed and may contribute to the enhanced catalytic performances of the supported monometallic nanoparticles. ${ }^{\mathbf{4 2 , 4 9}}$ In the aspect of LIB application, the silicon/reduced graphene oxide (Si/RGO) nanocomposites show a high reversible capacity and excellent rate capability. ${ }^{50}$ The RGO anchoring could act as both conductive agent and buffer layer for Si volume change in the charge-discharge process. According to the Feng et al., ${ }^{51-53}$ by employing graphene as outer shell to completely encapsulate 
metals, it can effectively avoid the inside metals from being destroyed in harsh environments. And we are devoted to research the effect of graphene incorporating $\mathrm{Au}$ on the pore size and catalytic activity of NPG.

Herein, we provide a facile method to fabricate nanocomposites of NPG and RGO by dealloying $\mathrm{Al}_{2} \mathrm{Au}$ ribbons and powders in the acid environment containing certain graphene oxide solution. During the dealloying process, GO was reduced by the reaction between $\mathrm{Al}$ atoms and $\mathrm{HCl}$ solution, further forming an $\mathrm{Al}-\mathrm{Au} / \mathrm{RGO}$ structure; then NPG/RGO nanocomposites were fabricated accompanying with the removal the residual $\mathrm{Al}$ in the $\mathrm{HCl}$ solution (Fig. 1). In a GO solution, the surface of the Al-Au alloy is positively charged accompanied by the $\mathrm{Al}$ atoms loses electrons, then the GO sheets can be easily partially reduced after accepting electrons because the abundant oxygen-containing functional groups exist in the surface of GO. The partially reduced GO sheets become hydrophobic and easy to restack on the $\mathrm{Al}-\mathrm{Au}$ alloy surface in order to minimize their surface energy. The residual $\mathrm{Al}$ can be removed by adding excessive $\mathrm{HCl}$ solution, forming nanoporous gold/reduced graphene oxides nanocomposites. In this process, thanks to their flexibility and ductility, RGO sheets intersperse randomly on the sphere-structure of NPG, further forming an armour-like structure.

\section{Experimental section}

\section{Materials synthesis}

A graphene oxide (GO) aqueous solution was synthesized by the typical modified Hummers' method. ${ }^{54}$ The pure bulk metals
(Au, 99.99\%; Al, 99.99\%) were purchased from Zhaojin Group Co., Ltd (Yantai, China), and Trillion Metals Co., Ltd (Beijing, China), respectively. Concentrated hydrochloric acid (AR, $37.5 \mathrm{wt} \%$ ), concentrated sulfuric acid (AR, $98.3 \mathrm{wt} \%$ ), potassium hydroxide (99.99 wt\%), methanol (GR) etc. were supplied by Sinopharm Chemical Reagent Co., Ltd. Firstly, the influence of graphene oxide (GO) on the dealloying process of precursor $\mathrm{Al}_{2} \mathrm{Au}$ ribbons was investigated. The prepared details can be referenced from our former works. ${ }^{31}$ Typically, several $\mathrm{Al}_{2} \mathrm{Au}$ ribbons (totally about $3 \mathrm{~g}$ ) were firstly soaked in certain GOconcentrated solution, then $10 \mathrm{wt} \% \mathrm{HCl}$ solution was slowly added into graphene oxide solutions, the final GO concentration $C_{\mathrm{GO}}$ of which varies from 0 to $100 \mathrm{ppm}$, respectively. Until no further bubbles were observed, the etching process finished. The nanocomposite ribbon samples dealloyed in the solutions with $C_{\mathrm{GO}}=0,50$, and $100 \mathrm{ppm}$ were labeled as S0, S1 and S2, respectively.

Subsequently, according to the consequences of the NPG/ RGO ribbons, the effect of GO on the dealloying process of $\mathrm{Al}_{2} \mathrm{Au}$ powders was further investigated. The $\mathrm{Al}_{2} \mathrm{Au}$ ingot was ball-milled into micro order powders using the high energy ballmilling. $1 \mathrm{~g} \mathrm{Al}_{2} \mathrm{Au}$ powders were first dispersed in GOconcentrated solution. After adding $\mathrm{HCl}$ solution, the final $C_{\mathrm{GO}}$ of dealloying solution is $50 \mathrm{ppm}$. The as-prepared nanocomposites powders were obtained after a series of centrifugation and washing. For the synthesis of blank NPG, the dealloying process is similar and the dealloying solution does not contain graphene oxide. Hereafter, the obtained NPG and NPG/RGO powder samples were marked as P0 and P1, respectively.
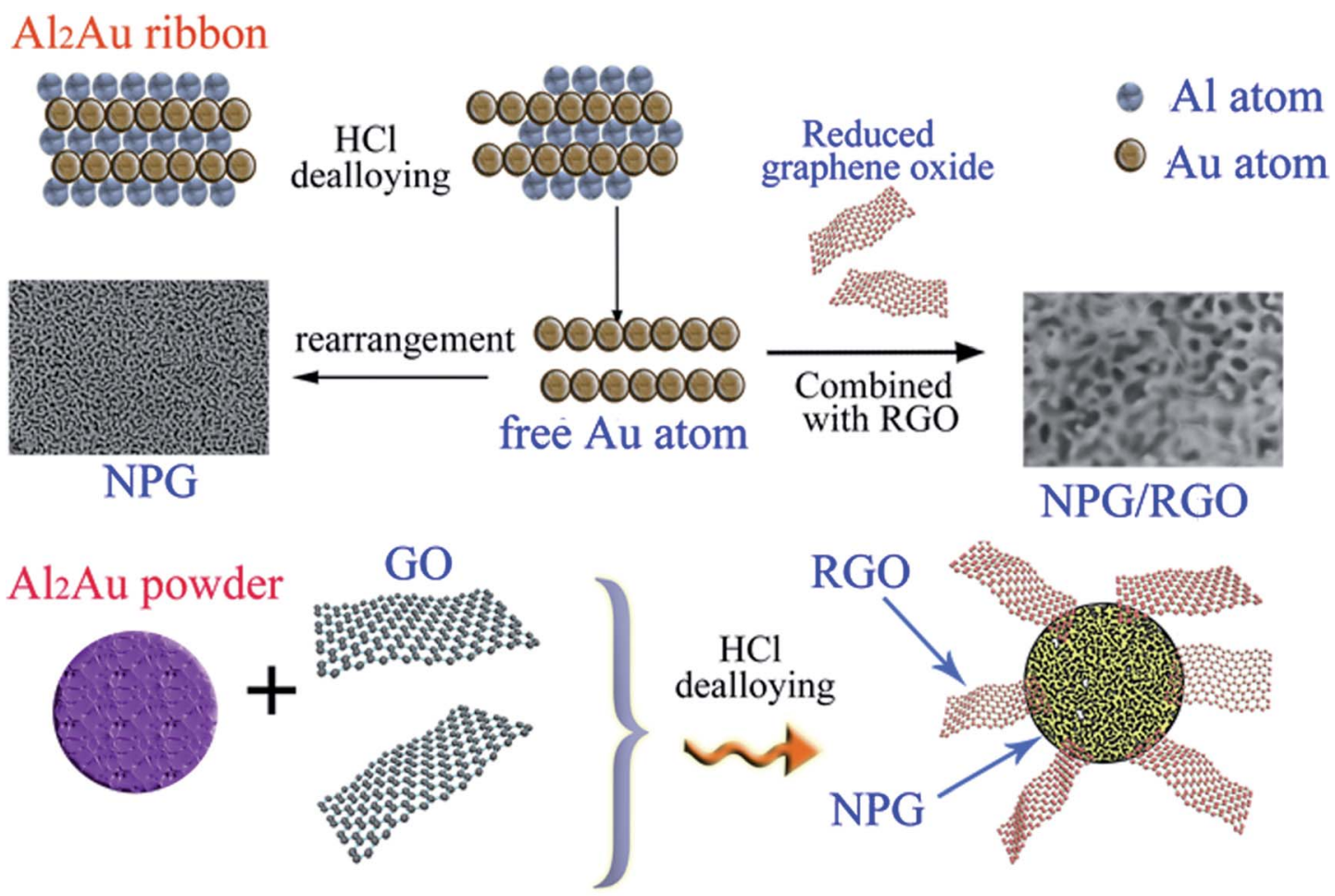

Fig. 1 Schematic illustration of the formation of nanocomposite ribbons and powders. 


\section{Microstructure characterization}

X-ray diffraction (Rigaku D/MAX 2500/PC diffractometer) was performed with $\mathrm{Cu} \mathrm{K} \alpha$ radiation. The lattice constant $a_{0}$ and the preferred orientation factors $F$ of (111) faces of samples were calculated by the extended Bragg equation and Lotgering method (eqn (S1) and $(\mathrm{S} 2) \dagger) .^{55,56}$ The specific calculation methods were displayed in ESI. $\uparrow$ The microstructure morphologies of nanocomposite ribbons and powders were investigated by a scanning electron microscope (SEM, Zeiss SUPRA 55) and a transmission electron microscope (TEM, JEOL JEM-2100) with selected-area electron diffraction (SAED) patterns. Some TEM specimens were also observed using high-resolution TEM (HRTEM). A Horiba Jobin-YNON co-focal laser Raman system was used to obtain the Raman spectra, equipping a He-Ne laser with an excitation wavelength of $532 \mathrm{~nm}$. Thermogravimetric analysis (TGA) was performed on a Mettler-Toledo TGA/ SDTA851e Thermo Analyzer from room temperature to $800{ }^{\circ} \mathrm{C}$ at a rate of $5{ }^{\circ} \mathrm{C} \mathrm{min}^{-1}$.

\section{Electrochemical measurements}

Cyclic voltammetry (CV) and other tests were operated on a $\mathrm{CHI}$ 660E electrochemical station (Chenhua instrument Ltd., Shanghai) with a three-electrode cell system to measure the electrocatalytic activities of nanocomposites samples for methanol electro-oxidation reaction (MOR). Nanocomposites ribbons were used as the working electrodes directly. For powder samples, the catalyst suspensions were made by sonicating a mixture of $2.0 \mathrm{mg}$ catalyst powders, $3.0 \mathrm{mg}$ XC-72 carbon powders, $1.5 \mathrm{~mL}$ isopropanol and $0.5 \mathrm{~mL}$ Nafion solution $(0.5 \mathrm{wt} \%)$ for $30 \mathrm{~min}$. Then a proper amount of the catalyst suspension was dripped on pre-polished $4 \mathrm{~mm}$ diameter glassy carbon (GC) electrodes for electrochemical measurements. A bright Pt plate was used as counter electrode. And a $\mathrm{Hg} / \mathrm{HgO}$ (1.0 M KOH) electrode (MMO) or a $\mathrm{Hg} / \mathrm{Hg}_{2} \mathrm{SO}_{4}$ electrode (MSE) were used as the reference electrode, respectively. Electrolytes that we selected were $0.5 \mathrm{M} \mathrm{KOH}+0.5 \mathrm{M}$ methanol and $0.5 \mathrm{M} \mathrm{H}_{2} \mathrm{SO}_{4}+0.5 \mathrm{M}$ methanol, respectively. The scanning rates $v$ of CVs were changed from 2 to $500 \mathrm{mV} \mathrm{s}^{-1}$. And the quasi steady-state anodic Tafel polarization analysis with the $v$ of $1 \mathrm{mV} \mathrm{s}^{-1}$ was also measured in order to further study the sample catalytic activity for MOR. To evaluate the durability of the nanocomposite powders for MOR, the chronoamperograms (CAs) were recorded for a period of $3600 \mathrm{~s}$ at a fixed potential of
$300 \mathrm{mV}$. All current densities were uniformed with the real surface of the samples.

\section{Results and discussion}

\section{Part 1: as-synthesized nanocomposite ribbons}

A. Crystal structure and constituent of the ribbon samples. As shown in Fig. 2a, the XRD patterns of NPG ribbon S0 and NPG/RGO composites S1 and S2 have four f.c.c. Au peaks (PDF no. 04-0784) with no obvious RGO peak, which is possibly due to the low content of the adsorbed GO. The lattice constant $a_{0}$ and the preferred orientation factors $F$ of (111) face $F_{(111)}$ of samples are listed in Table 1 . The $a_{0}$ of ribbons increase with increasing the GO concentration $\left(C_{\mathrm{GO}}\right)$ in dealloying process, and are larger than the $a_{0}$ of standard Au $(0.40786 \mathrm{~nm})$. After dealloying, NPG has two stress regions: $:^{57}$ in the effect of tension regions, the bonds between $\mathrm{Au}$ atoms are easy to stretch, leading to a larger $a_{0}$ (>0.40786 $\left.\mathrm{nm}\right)$, and oppositely the compression regions result in a smaller $a_{0}(<0.40786 \mathrm{~nm})$. Thus, the tensile stress exists in NPG/RGO ribbons (Table 1 ). In addition, $F_{(111)}$ values of ribbons are in the order: $\mathrm{S} 1>\mathrm{S} 2>\mathrm{S} 0$, which indicates a nonmonotonic effect of adding GO on $F_{(111)}$.

Recently, NPG has been widely applied as the substrate of surface-enhanced Raman scattering (SERS) spectroscopy due to its large surface area and 3D bicontinuous porous structure. ${ }^{50}$ As a good substrate material, the Raman spectrum of S0 exhibits a smooth curve with no obvious peak (Fig. 2b). After adding RGO, the peaks at 1320 and $1620 \mathrm{~cm}^{-1}$ in the curves of S1 and $\mathrm{S} 2$ are corresponding to the breathing mode of aromatic rings of graphene ( $\mathrm{D}$ band) and stretching mode of $\mathrm{sp}^{2}$ carbon ( $\mathrm{G}$ band), respectively. The intensity ratio $\left(I_{\mathrm{D}} / I_{\mathrm{G}}\right)$ of D-band and G-band usually stands for defect degree and a higher ratio exhibits more defects formed in the synthesizing process. As shown in Fig. $2 \mathrm{~b}$, the $I_{\mathrm{D}} / I_{\mathrm{G}}$ ratios of $\mathrm{S} 1$ and $\mathrm{S} 2$ samples are larger than 1.0, demonstrating that the RGO contains a large number of

Table 1 The lattice constants $a_{0}$ and the preferred orientation factors $F$ of (111) face $F_{(111)}$ of nanocomposite ribbons

\begin{tabular}{llll}
\hline Samples & S0 & S1 & S2 \\
\hline$a_{0}(\mathrm{~nm})$ & 0.40799 & 0.40803 & 0.40804 \\
$F_{(111)}$ & 0.0838 & 0.247 & 0.174
\end{tabular}
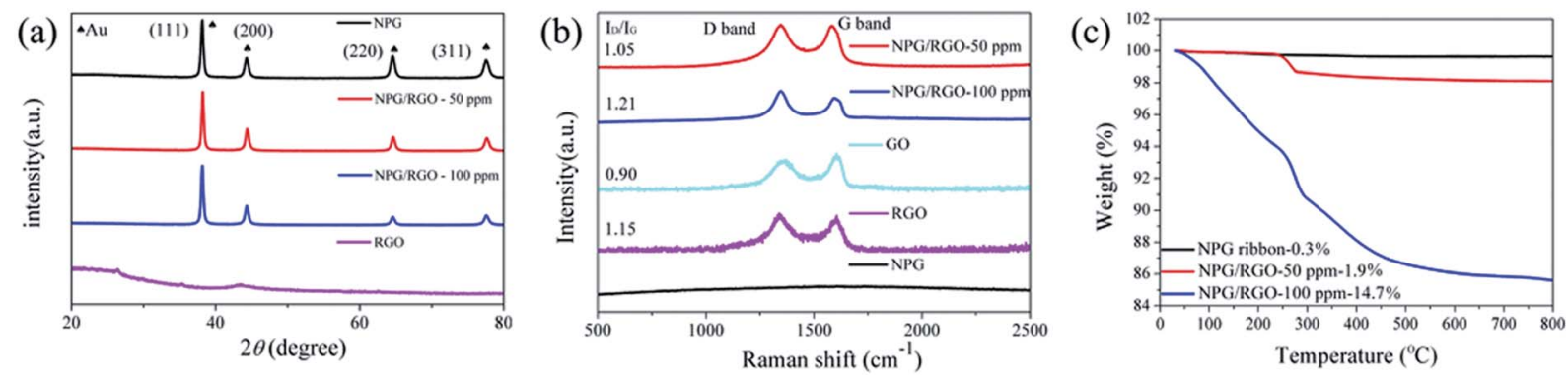

Fig. 2 (a) XRD patterns, (b) Raman spectra and (c) TGA curves of nanocomposite ribbons (S0-S2) with varying $C_{G O}(0-100$ ppm), respectively. 
disordered carbon atoms, i.e. defects. ${ }^{58}$ In addition, the present Raman spectra indicate that RGO can be effectively combined with NPG.

To further explore the thermal stability of ribbons, the weight ratio of RGO in the NPG/RGO ribbons was determined by TGA under an atmosphere of compressed air. As shown in Fig. 2c, S0 presents an almost smooth line due to its slight weight loss with the removal of trace absorbed water at $245{ }^{\circ} \mathrm{C}$, while the TGA curves of the S1 and S2 have a large loss and follow a similar trend in heating process. Except for the removal of absorbed water, the drastic weight loss starting at $245^{\circ} \mathrm{C}$ of S1 and S2 is also related to the pyrolysis of some oxygencontaining functional groups. The mass loss at $500{ }^{\circ} \mathrm{C}$ can be attributed to burning of RGO. ${ }^{53}$ Here, in terms of the TGA results, the weight ratios of RGO in S1 and S2 are about 1.9, and $14.7 \%$, respectively, confirming that the amount of RGO in NPG ribbons increases with increasing $C_{\mathrm{GO}}$ in dealloying process.

B. Microstructure of the as-synthesized nanocomposite. SEM was operated to demonstrate whether the dealloying strategy to prepare NPG/RGO nanocomposite ribbons is effective or not. S0 has a uniform 3D bicontinuous interconnecting structure, with the pore size of 50-100 nm (Fig. 3a-c). The grain boundaries can be seen clearly in the low magnification image, with the grain size distributed in $5 \mu \mathrm{m}$ (Fig. 3c). After adding GO solution in dealloying process, $\mathrm{S} 1$ has several transparent RGO layers in cicadas wing like shape anchored on the ligament/ channel of NPG (Fig. 3d-f). Here, RGO sheets are not totally covering on the NPG structure. When $C_{\mathrm{GO}}$ increases to $100 \mathrm{ppm}$, the RGO layers of S2 are much thicker and darker than that of S1 (Fig. 3g-i). Three samples all exhibit the maze-like structure with the uniform pore size.

The TEM images of NPG in Fig. $4 \mathrm{a}$ and $\mathrm{b}$ show that S0 has a ligament (dark-skeleton)-channel (bright region) structure with the pore size of 50-100 nm, being consistent with the SEM images in Fig. 3a-c. As shown in the HRTEM image (Fig. 4c), S0 has regular arranged lattice fringes with the same orientation, showing a single crystalline nature. And the lattice spacing $(0.234 \mathrm{~nm})$ of the single nanocrystal can be indexed as f.c.c. Au (111) reflection. In addition, the diffraction spots can be identified as Au (Fig. 4d), further verifying the single crystalline nature of So.

The low magnification TEM image of S1 (Fig. 5a) shows that the RGO layers (as indicated in red arrow) can be observed in the edge of the NPG. S1 has a ligament/channel structure and a number of RGO layers covered on the NPG (top right corner of Fig. 5b). The regular arranged lattice fringes with two different lattice spacings in HRTEM image (Fig. 5c) are corresponding to $\mathrm{Au}$ and graphene phases, respectively. In addition, the polycrystalline diffraction rings in the corresponding SAED pattern (Fig. 5d) can be indexed as Au (111), (200), (220), and (311) peaks, which verifies that the nanocomposite $\mathrm{S} 1$ has a tremendous amount of Au nanocrystals.

C. Electro-oxidation of methanol catalyzed by nanocomposite ribbons. Fig. 6 exhibits the CVs of S0, S1, and S2
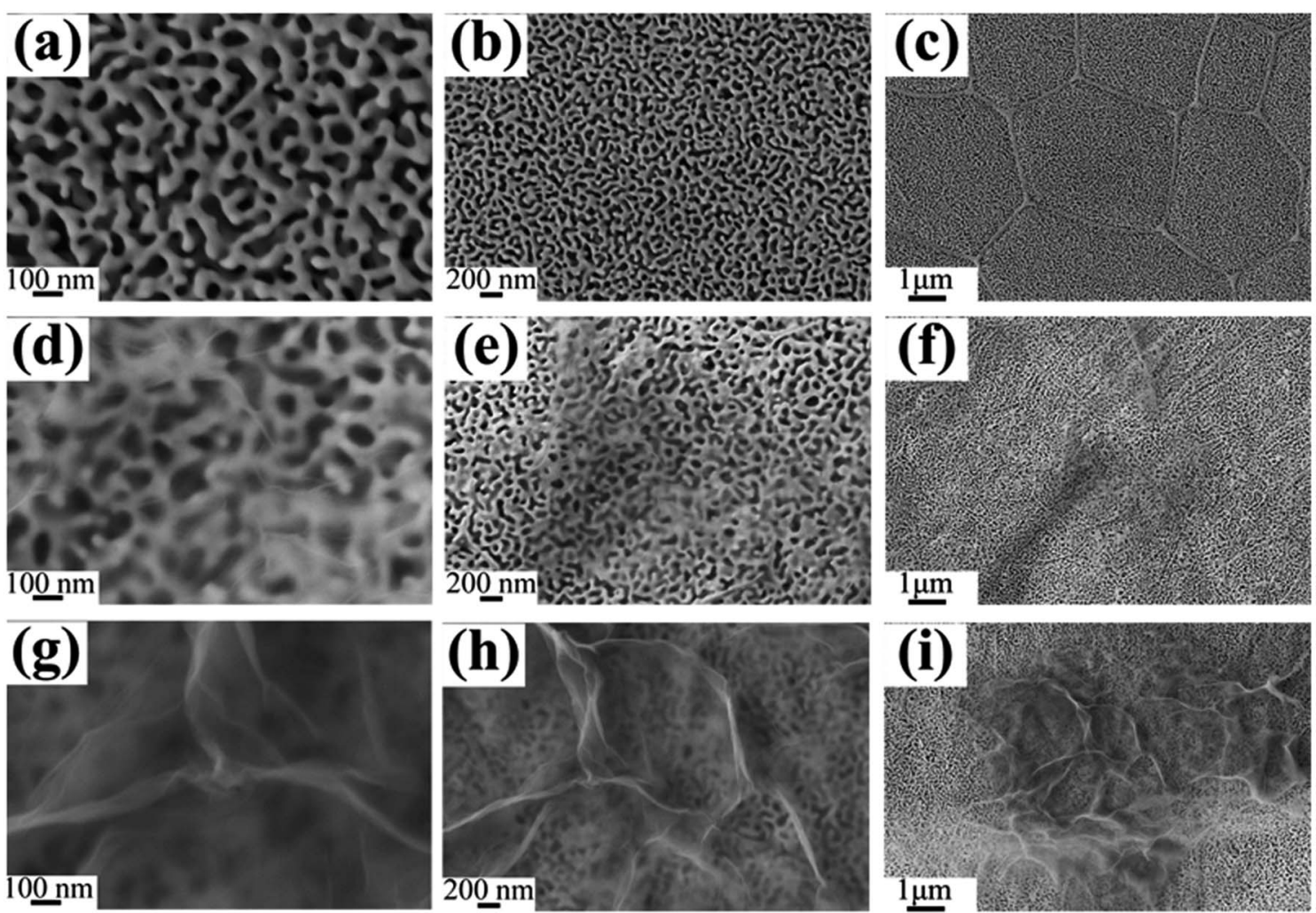

Fig. 3 Plain-view SEM micrographs of SO $(a-c), S 1(d-f)$, and S2 $(g-i)$, respectively. 

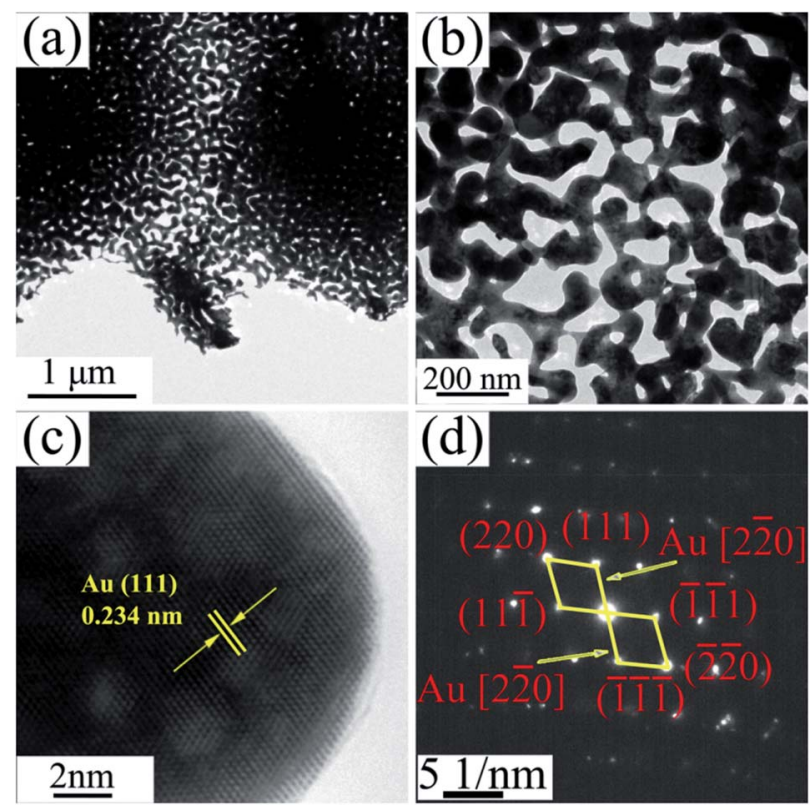

Fig. 4 (a) TEM image of SO, (b) the corresponding enlarged image, (c) HRTEM image and (d) the corresponding SAED pattern.

measured in $0.5 \mathrm{M} \mathrm{H}_{2} \mathrm{SO}_{4}$ solution. According to the oxygen adsorption measurement method, the real surface areas $\left(A_{\text {real }}\right)$ of S0, S1 and S2 electrodes are 1.45, 2.25, and $2.01 \mathrm{~cm}^{2}$, respectively. And the surface roughness factors $r_{\mathrm{f}}$ (denoted as the ratio between $A_{\text {real }}$ and geometry area $A_{\text {geom }}, 0.2 \mathrm{~cm}^{2}$ ) of S0, $\mathrm{S} 1$ and $\mathrm{S} 2$ are $7.25,11.25$, and 10.05 , respectively. Here, S1 has a maximal $A_{\text {real }}$. The electro-catalytic activities like CVs of ribbon electrodes for MOR were shown in Fig. 7, 8 and S1-S4 $\uparrow$ at $v=2-$ $500 \mathrm{mV} \mathrm{s}^{-1}$ in $0.5 \mathrm{M} \mathrm{KOH}+0.5 \mathrm{M}$ and $0.5 \mathrm{M} \mathrm{H}_{2} \mathrm{SO}_{4}+0.5 \mathrm{M}$
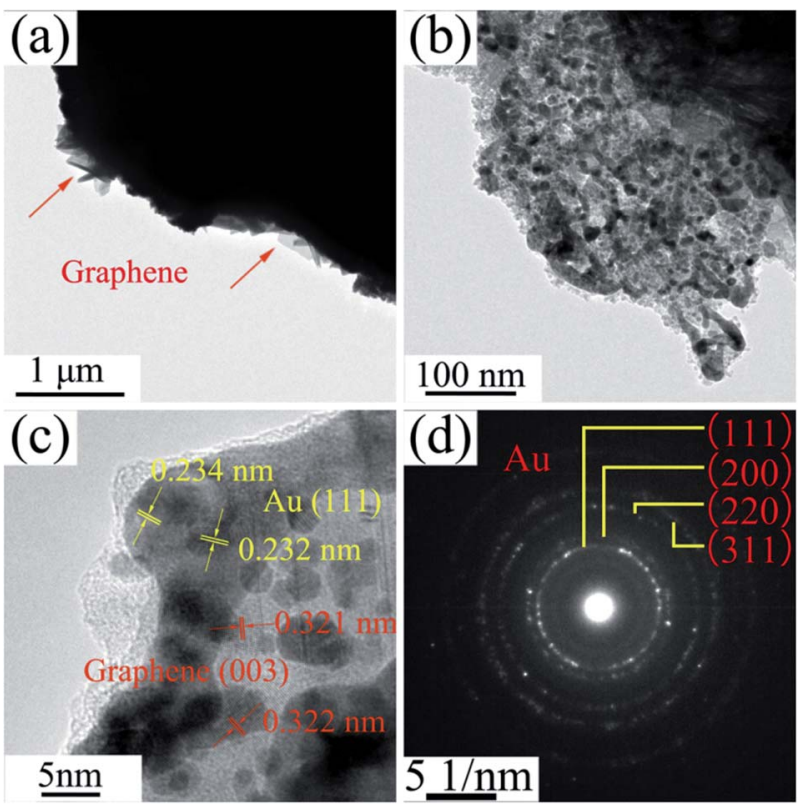

Fig. 5 (a) TEM image of S1, (b) the corresponding enlarged image, (c) HRTEM image and (d) the corresponding SAED pattern.

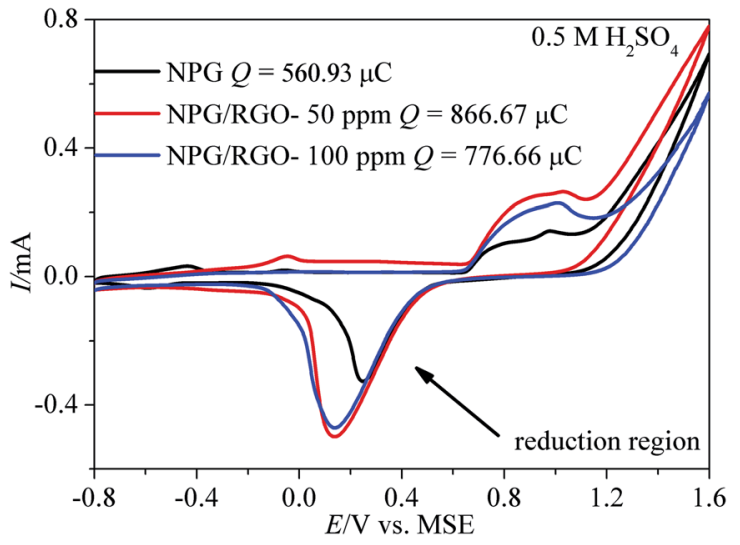

Fig. 6 Cyclic voltammograms (CVs) of SO-S2 electrodes measured in $0.5 \mathrm{M} \mathrm{H}_{2} \mathrm{SO}_{4}$ solution. Scan rate $v$ : $50 \mathrm{mV} \mathrm{s}^{-1}$.

methanol solutions. Apparently, increasing the $v$ could increase the current density of CVs of samples.

Generally, the CVs test is a major method to analyze the electrochemical behavior of an electrode. More analysis details can be obtained from our former reports. ${ }^{32}$ In order to better understand the mechanism of MOR more clearly, independent CV curve of S1 electrode tested in alkaline solution is shown in Fig. S5. $\dagger$ Briefly, MOR on Au electrode occurs in two regions with different mechanisms. ${ }^{12,59,60}$ As shown in Fig. S5, $\dagger$ in the lower potential region from -0.6 to $0.4 \mathrm{~V} v s$. MMO, MOR commences in the surface of oxide-free electrode. The subpeak at $\sim-0.3 \mathrm{~V} v$ s. MMO (peak 1) is attributed to the emergence of the "pre-oxidation species" (eqn (1)), and $\lambda(0-1)$ represents the charge-transfer coefficient. ${ }^{61}$

$$
\mathrm{Au}+\mathrm{OH}^{-}-\lambda \mathrm{e}^{-} \rightarrow \mathrm{Au}-\mathrm{OH}_{\mathrm{ads}}^{(1-\lambda)-}
$$

With increasing potential, $\mathrm{Au}-\mathrm{OH}_{\mathrm{ads}}{ }^{(1-\lambda)-}$ is oxidized to $\mathrm{AuO}$, and formate is the mainly product of MOR through a fourelectron-transfer reaction as following: ${ }^{12,60}$ We can observe the appearance of peak 2 in Fig. S5. $\dagger$

$$
\begin{gathered}
\mathrm{Au}-\mathrm{OH}_{\mathrm{ads}}^{(1-\lambda)-}+\mathrm{OH}^{-}-(2-\lambda) \mathrm{e}^{-} \rightarrow \mathrm{AuO}+\mathrm{H}_{2} \mathrm{O} \\
\mathrm{CH}_{3} \mathrm{OH}+5 \mathrm{OH}^{-}=\mathrm{HCOO}^{-}+4 \mathrm{H}_{2} \mathrm{O}+4 \mathrm{e}^{-}
\end{gathered}
$$

As potential surpasses $0.45 \mathrm{~V}$ vs. MMO, the oxidation of methanol could be weakened by the transformation of $\mathrm{Au}-$ $\mathrm{OH}_{\mathrm{ads}}{ }^{(1-\lambda)-}$ to AuO, corresponding to the current density decreases. Benefiting from the re-exposed of the fresh $\mathrm{Au}$ surface oxide, the oxidation of methanol to carbonate emerged on the gold oxides via a six-electron-transfer reaction (eqn (4)), leading to an obvious increment of anodic current densities for MOR (peak 3). ${ }^{12,62}$

$$
\mathrm{CH}_{3} \mathrm{OH}+8 \mathrm{OH}^{-}=\mathrm{CO}_{3}{ }^{2-}+6 \mathrm{H}_{2} \mathrm{O}+6 \mathrm{e}^{-}
$$

The step by step reaction is helpful for the oxidation of intermediates at high potential, which can eliminate the possible catalyst poisoning. ${ }^{17}$ In the following negatively 

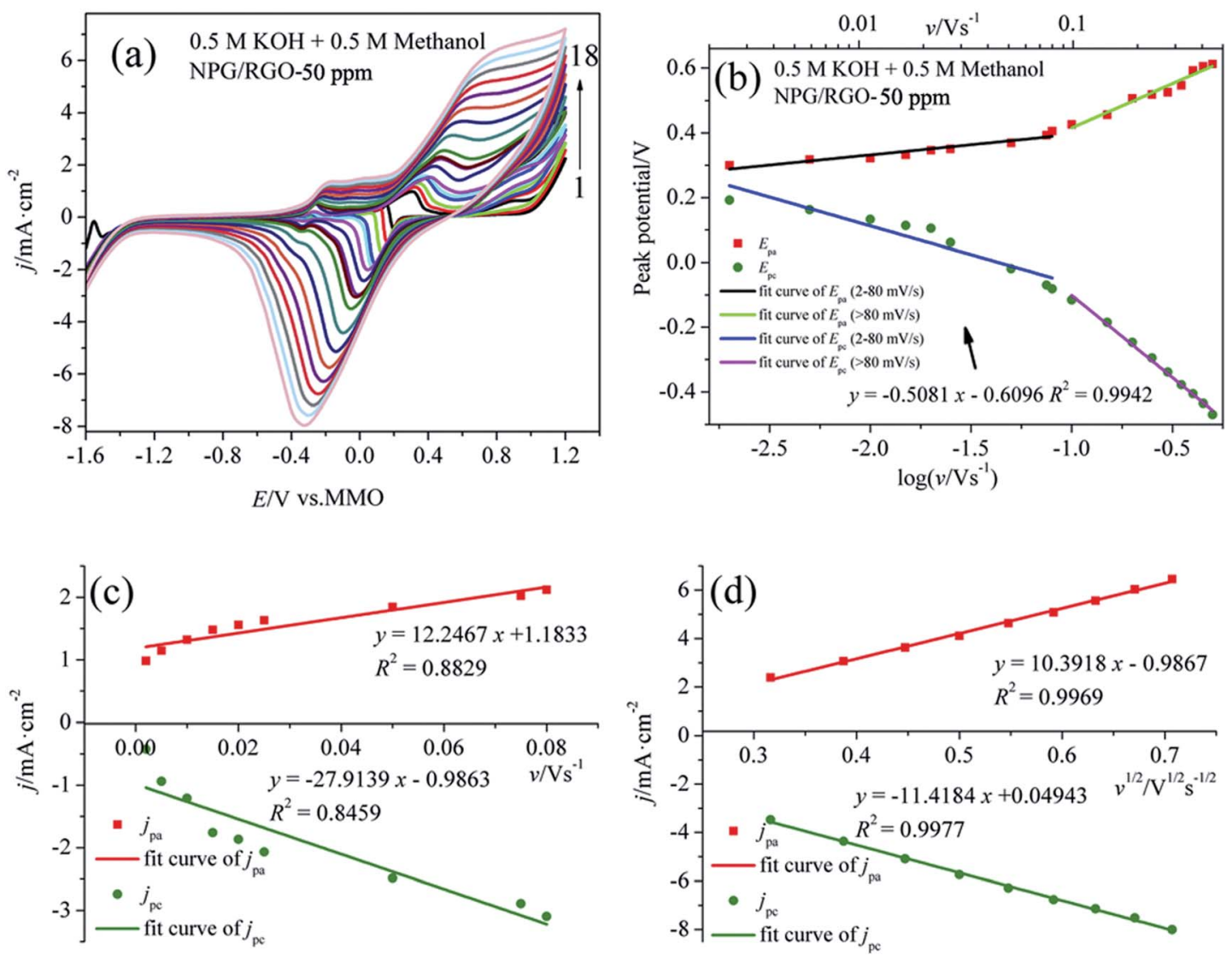

Fig. 7 (a) CVs of S1 electrode in $0.5 \mathrm{M} \mathrm{KOH}+0.5 \mathrm{M}$ methanol solution at various scan rates $v$ : (1) $0.002,(2) 0.005$, (3) 0.01 , (4) 0.015 , (5) 0.02 , (6) 0.025, (7) 0.05, (8) 0.075, (9) 0.08, (10) 0.1, (11) 0.15, (12) 0.2, (13) 0.25, (14) 0.3, (15) 0.35, (16) 0.4, (17) 0.45 and (18) $0.5 \vee \mathrm{s}^{-1}$, (b) plot of $E_{\mathrm{p}} v \mathrm{vs}$. log $v$ for $C V s$ for anodic and cathodic peaks, (c) dependency of $j_{\mathrm{pa}}$ and $j_{\mathrm{pc}}$ on lower values of $v\left(0.002-0.08 \mathrm{~V} \mathrm{~s}{ }^{-1}\right)$, and (d) on $v^{1 / 2}$ at higher values of $v(v$ $>0.08 \mathrm{~V} \mathrm{~s}^{-1}$.

sweeping, MOR re-starts according to eqn (3) and is accompanying with the removal of dense AuO; hence, it increases the absolute values of the corresponding oxidation current densities (peak 4). ${ }^{12,62}$ The small peak at around $-0.30 \mathrm{~V} v$ s. MMO (peak 5) is related with the oxygen reduction reaction in the solution. Fig. 7b shows the $E_{\mathrm{pa}} v s . \log v$ and $E_{\mathrm{pc}} v s . \log v$ curves deduced from the measured CVs. Apparently, the potential difference $\Delta E_{\mathrm{p}}\left(E_{\mathrm{pa}}-E_{\mathrm{pc}}\right)$ increases with increasing $v$, suggesting the charge transfer kinetic limitation in the reaction. ${ }^{63}$

It is well known that the electron-transfer coefficient $(\alpha)$, and apparent charge-transfer rate constant $k_{\mathrm{s}}\left(\mathrm{s}^{-1}\right)$ can be obtained from the Laviron theory (eqn (S3)-(S5) †) if $\Delta E_{\mathrm{p}}>0.2 / n \mathrm{~V} \cdot{ }^{64} \mathrm{We}$ selected the curve of $E_{\mathrm{pc}} v s . \log v$ and obtained $\alpha$ and $k_{\mathrm{s}}(0.058$ and $0.053 \mathrm{~s}^{-1}$ ), which indicates that the electrochemical process is the major rate limiting step according to the former reports. ${ }^{63,65}$ Usually, a larger $k_{\mathrm{s}}$ could represent a faster oxidation process. In addition, the linear relationship between $v$ and peak current densities in $2-80 \mathrm{mV} \mathrm{s}^{-1}$ can be observed in Fig. $7 \mathrm{c}$, which is ascribed to the activity of the surface redox couple. ${ }^{66}$ Here, the surface coverage $\left.\Gamma^{*}(\mathrm{~mol} \mathrm{~cm})^{-2}\right)$ of the redox species, i.e., the immobilized active species, is deduced according to eqn (S6). $\dagger^{67,68}$ The calculated $\Gamma^{*}$ of S1 electrode is $5.10 \times 10^{-6} \mathrm{~mol}$ $\mathrm{cm}^{-2}$ after averaging the cathodic and anodic current densities. On the other hand, when $v>80 \mathrm{mV} \mathrm{s}^{-1}$, there is a good linear relation between the current densities of anodic/cathodic peaks and $v^{1 / 2}$ (Fig. $7 \mathrm{~d}$ ), leading to a diffusion control step. ${ }^{66}$

Fig. 8a shows the CVs of $\mathrm{S} 1$ electrode in $0.5 \mathrm{M} \mathrm{H}_{2} \mathrm{SO}_{4}+0.5 \mathrm{M}$ methanol solution at different $v$, where the "pre-oxidation species" is absent due to the low $\mathrm{OH}^{-}$concentration in the acid electrolyte. Apparently, a linear relationship between $E_{\mathrm{p}}$ and $\log v$ can be observed in Fig. 8b. Using the above mentioned method, the deduced $\Gamma^{*}, \alpha$, and $k_{\mathrm{s}}$ of samples in two kinds of electrolytes are summarized in Table 2 . In the presence of $\mathrm{OH}^{-}$, the $\Gamma^{*}$ and $k_{\mathrm{s}}$ of electrodes are higher than those in the absence of $\mathrm{OH}^{-}$, suggesting that $\mathrm{OH}^{-}$plays an important role in MOR. ${ }^{17}$ Moreover, the $\Gamma^{*}$ and $k_{\mathrm{S}}$ of S1 are higher than those of S2 and S0. Meanwhile, the current densities of oxidation and reduction peaks of S1 are higher than those of the other samples (Figs. 7, 8, S1-S4), suggesting that the activity for MOR of S1 is the highest. For comparison, the CVs of electrodes in acid and alkaline solutions without methanol are exhibited in Fig. S6. $\dagger$ The $E_{\mathrm{p}} v s$. $\log v$ of ribbon electrodes is given in Fig. S7. $\dagger$ Fig. S8 $\dagger$ shows the CVs of S1 electrode with 50 cycles in alkaline and acid solutions with the scan rate $v$ of $50 \mathrm{mV} \mathrm{s}^{-1}$. It can be found that with increasing the cycle, the current densities of oxidation peaks increase, indicating that electrode exhibits a good durability. ${ }^{69}$

Tafel polarization curves of ribbon electrodes in two kinds of electrolytes are shown in Fig. 9. The measured voltage range in 

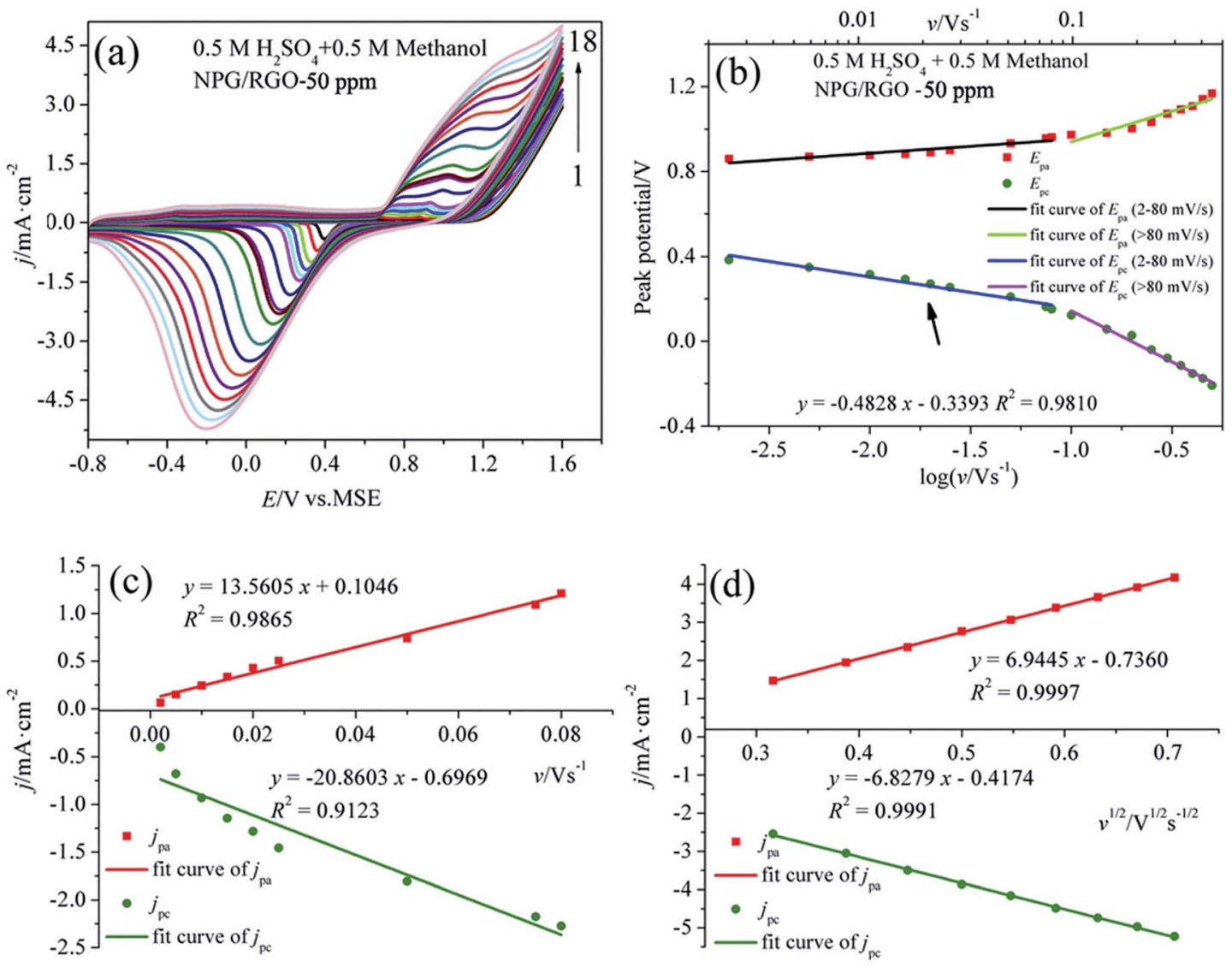

Fig. 8 (a) $\mathrm{CVs}$ of $\mathrm{S} 1$ electrode in $0.5 \mathrm{M} \mathrm{H}_{2} \mathrm{SO}_{4}+0.5 \mathrm{M}$ methanol solution at various scan rates $v$, (b) plot of $E_{\mathrm{p}} v s$. log $v$ for $C V s$ for anodic and cathodic peaks, (c) dependency of $j_{\mathrm{pa}}$ and $j_{\mathrm{pc}}$ on lower values of $v$ and (d) on $v^{1 / 2}$ at higher values of $v$.

alkaline acid solutions were $-0.6-0.2 \mathrm{~V}$ vs. MMO, and 0-0.5 V vs. MSE, respectively. Several Tafel parameters such as the Tafel slopes $b$, exchange current densities $j_{0}$, and corrosion potential $E_{\text {corr }}$ can be acquired according to eqn (S7)-(S9), $\uparrow^{\mathbf{7 0 , 7 1}}$ which are listed in Table 3. Moreover, there are current plateaus in the anodic parts in two solutions (Fig. 9b), demonstrating that in this region the charge transfer control is the leading step. ${ }^{72,73}$ The deduced $b, j_{0}$ and $E_{\text {corr }}$ confirm the highest activity of S1 electrode for MOR.

\section{Part 2: as-synthesized nanocomposite powders}

Besides the nanocomposite ribbon results in Part 1, the effect of $\mathrm{GO}$ on the dealloying process of $\mathrm{Al}_{2} \mathrm{Au}$ powders was further investigated.
A. Crystal structure and constituent of powders samples. The structure details such as XRD patterns and TEM images of powder precursor crushed from ingot are displayed in Fig. S9 and $\mathrm{S} 10 . \dagger$ The XRD patterns and Raman spectra of P0, P1, GO, and RGO are shown in Fig. 10 together with the TGA curves of $\mathrm{P} 0$ and P1. The Au peaks of P0 are sharper than P1 (Fig. 10a and b). The $a_{0}$ of P0 and P1 powders (0.40769 and $\left.0.40667 \mathrm{~nm}\right)$ are smaller than that of the standard $\mathrm{Au}(0.40786 \mathrm{~nm})$. Hence, the compressive stress is dominant in powder sample. ${ }^{32,57}$ In addition, the $F_{(111)}$ values of $\mathrm{P} 0$ and $\mathrm{P} 1$ powders are 0.006 and 0.0187 , respectively. Accompanying with the reduction of GO, there is no obvious GO peaks in XRD patterns of P1. The enlarged XRD patterns show that the broaden diffractions of P1 and RGO

Table 2 The surface coverage of the redox species $\Gamma^{*}$, electron-transfer coefficient $\alpha$ and apparent charge-transfer rate constant between the electrode and the surface-deposited layer $k_{\mathrm{s}}$ obtained from CVs of ribbon electrodes with $v=2-80 \mathrm{mV} \mathrm{s}$ in alkaline and acid solutions, respectively

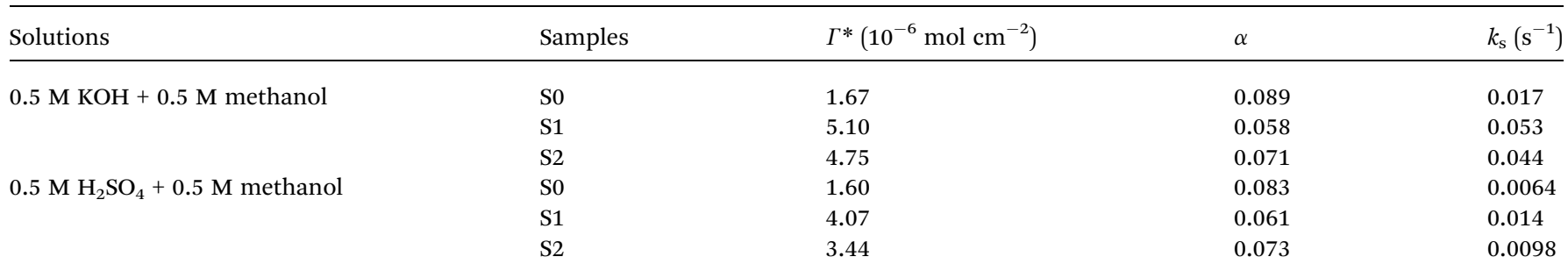



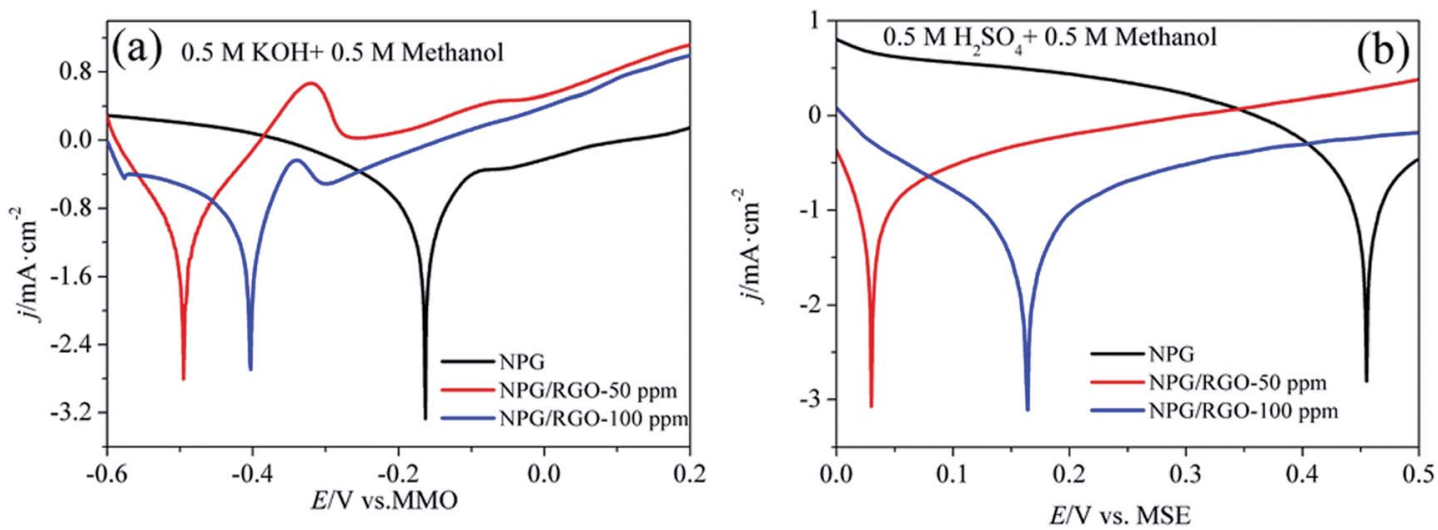

Fig. 9 Tafel curves of SO-S2 electrodes in (a) $0.5 \mathrm{M} \mathrm{KOH}+0.5 \mathrm{M}$ methanol and (b) $0.5 \mathrm{M} \mathrm{H}_{2} \mathrm{SO}_{4}+0.5 \mathrm{M}$ methanol solutions, respectively. $v$ : $1 \mathrm{mV}$ $\mathrm{s}^{-1}$.

diffractions are overlapped (Fig. 10b). The broadened peaks of $\mathrm{P} 1$ are probably attributed to the RGO.

The intensity of D band of P1 is slightly higher than that of G band in Raman spectrum (Fig. 10c), indicating that the RGO in P1 contains a large number of disordered carbon atoms and defects. RGO can be effectively combined with the nanostructure of NPG according to the Raman spectra results. The mass loss at around $500{ }^{\circ} \mathrm{C}$ is probably attributed to burning of RGO (Fig. 10d) ${ }^{53}$ and the weight percent of RGO in P1 samples are about $8.6 \%$.

B. Microstructure of the as-synthesized nanocomposite powders. As shown in Fig. S11, $\uparrow$ SEM images of P0 is similar with $\mathrm{S} 0$ except for the certain ligament coarsening. SEM images of P1 show a uniform maze-like structure with the attachment of several transparent RGO layers, accompanying with broadening of ligament (Fig. 11a and b). As shown in Fig. 11c and d, the sphere-structure NPG is surrounded by the RGO clusters. During milling the precursor ingot, RGO sheets intersperse randomly on the spherical NPG powders to reduce their surface energy and form an armour structure. We suppose that the unique structure plays a facilitating role in the electro-catalytic behavior of NPG.

The typical TEM images of P0 are analogous to S0 and not shown here. In TEM images of P1 (Fig. 12a-c), gray RGO layers are combined with the dark NPG in a ligament/channel structure. The corresponding SAED pattern (Fig. 12d) consists of polycrystalline diffraction rings and is consistent with those in
Fig. 5d, which verifies that the nanocomposite powder sample is also composed of a tremendous amount of Au nanocrystals.

C. Electro-oxidation towards methanol of as-synthesized nanocomposites samples. As shown in CVs of P0 and P1 in alkaline methanol solution (Fig. 13a and b), the oxidation peaks $\mathrm{H}_{1}$ and $\mathrm{H}_{2}$ in the low potential regions (-0.6-0.4 V vs. MMO) represent the formation of "pre-oxidation species" (eqn (1)) and the oxidation of methanol to formates (eqn (2) and (3)), respectively. When potential is higher than $0.45 \mathrm{~V} v s$. MMO, the formation of peak $\mathrm{H}_{3}$ is associated to the methanol oxidation via eqn (4), leading to the obvious increase of the anodic current density. An obvious reduction peak $\mathrm{H}_{4}$ can be observed in the negatively-going scan, which is related to the removal of dense AuO layer, and further stimulate the eqn (1) reaction.

The MOR behavior of $\mathrm{P} 0$ and $\mathrm{P} 1$ electrodes in acid electrolyte is similar to alkaline solution except for $\mathrm{H}_{1}$ peaks (Fig. 13c and d). In both cases, the current densities of $\mathrm{P} 1$ electrode are higher than that of P0 electrode. Tafel curves of P0 and P1 electrodes are shown in Fig. 14. According to eqn (S7)-(S9), $\uparrow$ the parameters obtained from Tafel curves of electrodes are listed in Table 4. These parameters further verify that $\mathrm{P} 1$ has a higher catalytic activity for MOR than P0 electrode, consisting with the CVs results. The stability of a catalyst is an important requirement for its practical applications. In order to evaluate the stability of P0 and P1 for MOR, chronoamperograms (CAs) are recorded for a period of $3600 \mathrm{~s}$ at a fixed potential of $300 \mathrm{mV}$ in alkaline (Fig. 14c) and acid solutions (Fig. 14d), respectively. For P0 and

Table 3 The corrosion potential $E_{\text {corr }}(\mathrm{V})$, anodic slope $\beta_{\mathrm{a}}\left(\mathrm{mV} \mathrm{dec} \mathrm{c}^{-1}\right)$, and exchange current density $j_{0}\left(\mathrm{~mA} \mathrm{~cm}^{-2}\right)$ obtained from Tafel curves of ribbon electrodes in alkaline and acid solutions, respectively

\begin{tabular}{|c|c|c|c|c|}
\hline Solutions & Samples & $E_{\text {corr }}(\mathrm{V})$ & $\beta_{\mathrm{a}}\left(\mathrm{mV} \mathrm{dec}{ }^{-1}\right)$ & $j_{0}\left(\mathrm{~mA} \mathrm{~cm}^{-2}\right)$ \\
\hline \multirow[t]{2}{*}{$0.5 \mathrm{M} \mathrm{KOH}+0.5 \mathrm{M}$ methanol } & So & -0.162 & 160.2 & 3.25 \\
\hline & S1 & -0.495 & 38.8 & 8.01 \\
\hline \multirow[t]{3}{*}{$0.5 \mathrm{M} \mathrm{H}_{2} \mathrm{SO}_{4}+0.5 \mathrm{M}$ methanol } & So & 0.455 & 186.0 & 2.67 \\
\hline & S1 & 0.030 & 77.5 & 7.25 \\
\hline & $\mathrm{S} 2$ & 0.164 & 89.3 & 5.37 \\
\hline
\end{tabular}



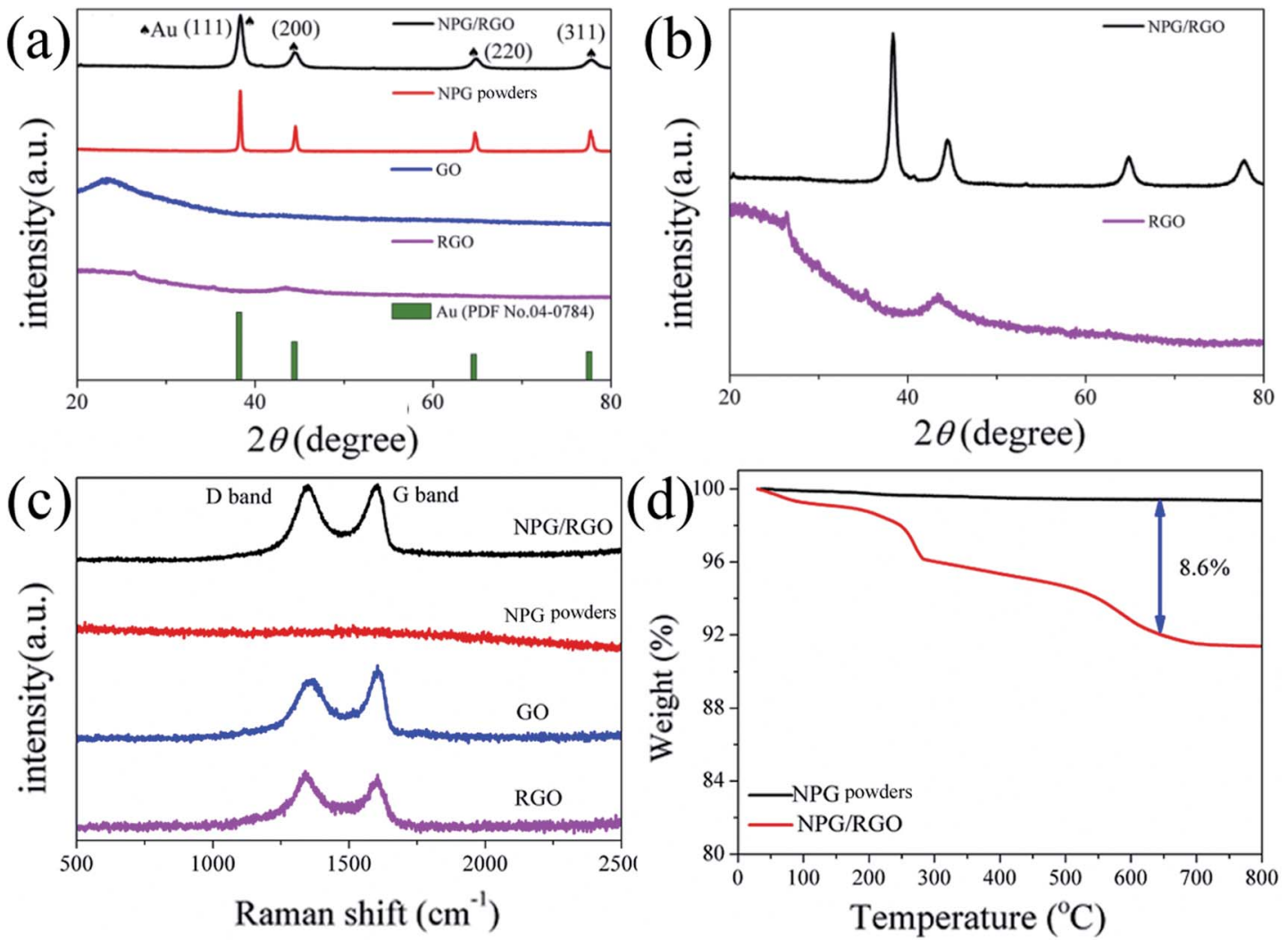

Fig. 10 (a) XRD patterns of nanocomposite powders P0, P1, GO, and RGO, (b) enlarged XRD patterns of P1 and RGO, (c) Raman spectra of P0, P1, $\mathrm{GO}$, and $\mathrm{RGO}$ and (d) TGA curves of PO and P1, respectively.

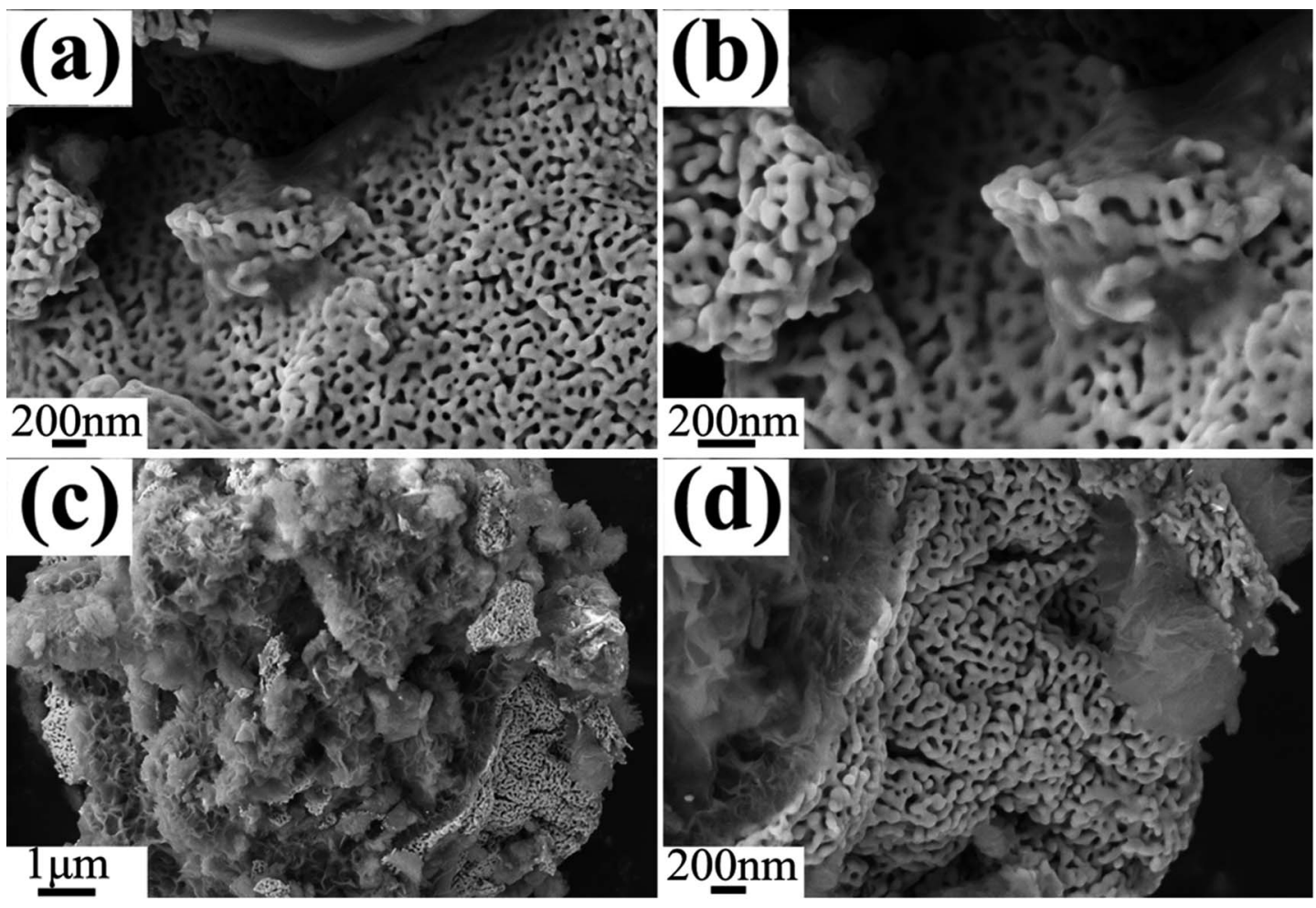

Fig. 11 Plain-view SEM micrographs (a and c) of P1, (b) and (d) are the corresponding magnification images of (a) and (c). 

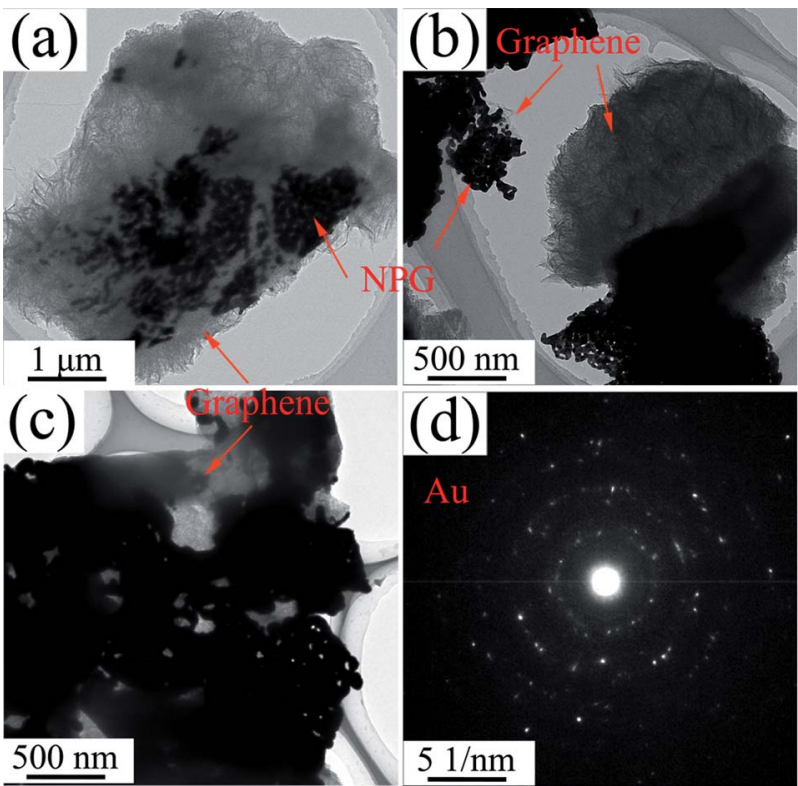

Fig. $12(a-c)$ TEM images and (d) SAED image of P1.

P1 electrodes, a rapid current decay appears within the limited seconds, accompanying by a slow drop until it reaches a smooth state. According to the literature ${ }^{74}$ the formation of double layer capacitance leads to the fast drop at first, and the following decay of the CAs is related to the accumulation of intermediate species during the process of methanol decomposition. The current density gradually reaches a quasi-equilibrium steady state with the further polarization. Moreover, the current density for P1 in both solutions is higher than that for P0 electrode in the whole process, indicating that P1 exhibits a relatively higher activity for MOR. Fig. $\mathrm{S} 12 \dagger$ also presents SEM images of P1 electrode after electrochemical tests, implying the marvelous structural stability of P1 electrode.

\section{Part 3: catalytic mechanism of NPG/RGO nanocomposites}

By adding moderate GO in dealloying process, we have obtained the NPG/RGO nanocomposite ribbons and powders with high activity for MOR. The high activity for MOR of NPG/RGO nanocomposites can be explained as follows.

Firstly, the activity for MOR of samples is in the following order: $\mathrm{S} 1>\mathrm{S} 2>\mathrm{S} 0$ and $\mathrm{P} 1>\mathrm{P} 0$. The $F_{(111)}$ of ribbon samples ranks as $\mathrm{S} 1>\mathrm{S} 2>\mathrm{S} 0$ (Table 1 ) and the $F_{(111)}$ of powder samples is $\mathrm{P} 1>\mathrm{P} 0$. According to the report, ${ }^{75}$ the anodic current density of $\mathrm{Au}$ (111) is the highest compared to those of $\mathrm{Au}$ (110) and (100), demonstrating that under the same conditions, Au (111) is more active than the other faces. This result can also be proved in our former works. ${ }^{32,76}$ We speculated that the formation of the low-index crystal plane (111) can be effected by the reduction of GO. The specific formation mechanism can be further investigated.
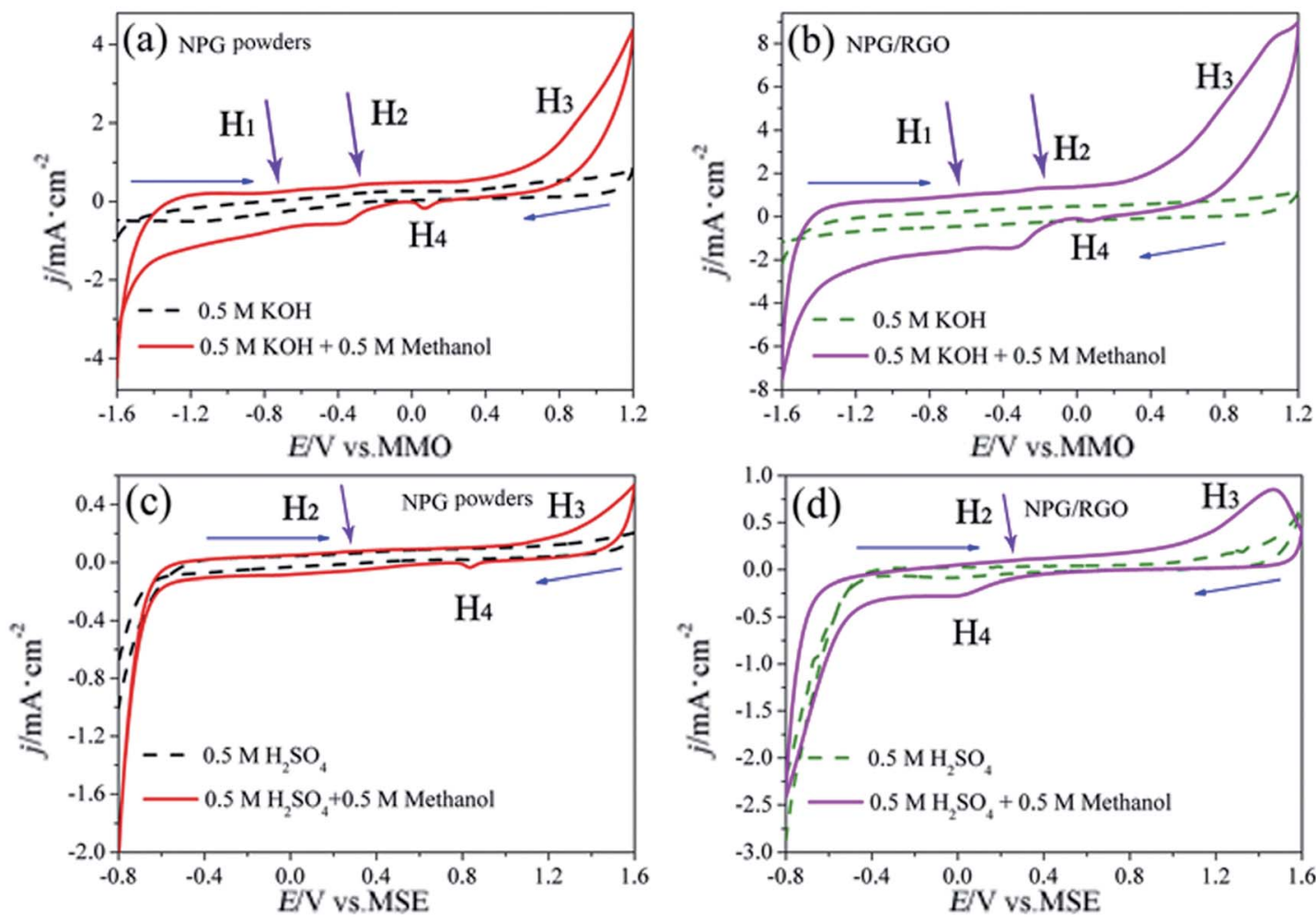

Fig. $13 \mathrm{CVs}$ of $\mathrm{PO}$ and $\mathrm{P} 1$ electrodes in $0.5 \mathrm{M} \mathrm{KOH}+0.5 \mathrm{M}$ methanol solution (solid lines in (a) and (b)), $0.5 \mathrm{M} \mathrm{KOH}$ solution (dash lines in (a) and (b)), $0.5 \mathrm{M} \mathrm{H}_{2} \mathrm{SO}_{4}+0.5 \mathrm{M}$ methanol solution (solid lines in (c) and (d)), and $0.5 \mathrm{M} \mathrm{H}_{2} \mathrm{SO}_{4}$ solution (dash lines in (c) and (d)), respectively, scan rates v: $50 \mathrm{mV} \mathrm{s}^{-1}$. 

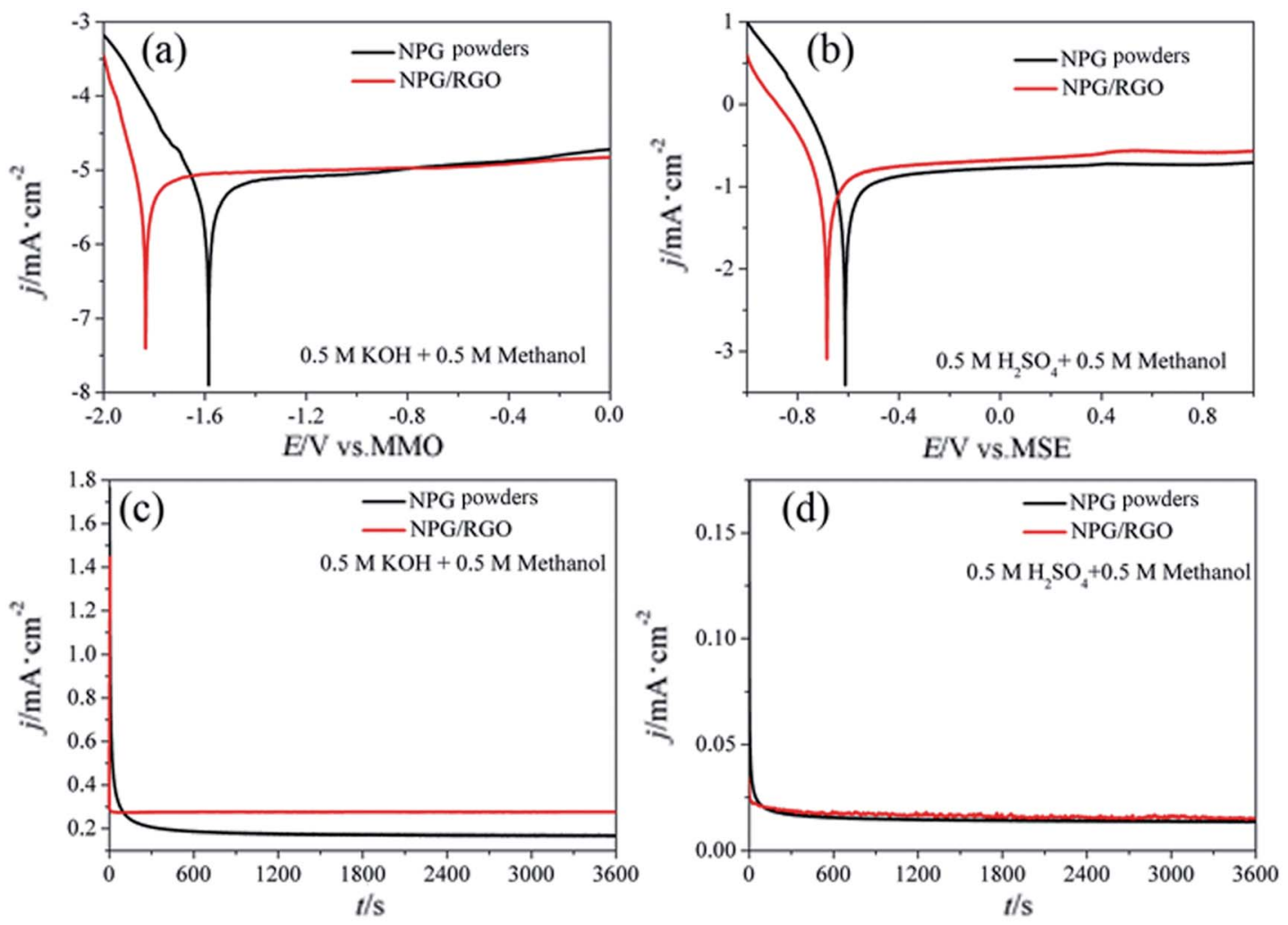

Fig. 14 Tafel curves of $\mathrm{PO}$ and $\mathrm{P} 1$ electrodes in (a) $0.5 \mathrm{M} \mathrm{KOH}+0.5 \mathrm{M}$ methanol and (b) $0.5 \mathrm{M} \mathrm{H}_{2} \mathrm{SO}_{4}+0.5 \mathrm{M}$ methanol solutions, respectively. v:

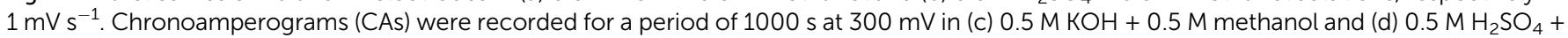
$0.5 \mathrm{M}$ methanol solutions, respectively.

Secondly, raising $r_{\mathrm{f}}$ of a catalyst can improve its catalytic activity due to two facts: ${ }^{18}(1)$ the $A_{\text {real }}$ of nanocomposites can be extended by the attachment of RGO sheets and supply more active sites for MOR; (2) the interconnected nanoporous channels of NPG can provide a faster pathway for transfering charge/ ions with a larger pore size.

Finally, S0 has a single crystal structure with a regular crystal face arrangement (Fig. 4), but S1 and P1 bear a polycrystal structure with a tremendous amount of Au nanocrystals as well as a few RGO (Fig. 5 and 12). More grain boundaries and defects exist in the nanocrystal structure of S1 and P1, compared to the single crystal. Also, according to XRD results (Fig. 2a and 10a), tensile stresses and compressive stresses exist in ribbon and powder samples, respectively. Material microstress can facilitate the catalytic activity of nanocomposite samples in the catalysis process..$^{57,77}$ Raman results show that RGO contains a large number of disordered carbon atoms, i.e. a large amount of defects. ${ }^{58}$ The defects of RGO can help ions/electrons to transfer in electrochemical reaction process. In addition, according to the report of Bäumer $e t$ al.,$^{30}$ the traced residual $\mathrm{Al}$ impurities undetected by XRD are crucial for the excellent oxidative activity of NPG and could also contribute to the activity of $\mathrm{Au}$ nanostructures. Grain boundary, stress, RGO defects and residual $\mathrm{Al}$ atoms are four kinds of defects in NPG/ RGO ribbon and powder nanocomposites, which can benefit the catalytic activity of NPG. ${ }^{78}$

In short, in the cooperation of the participation of RGO sheets and unique ligament/channel nanostructure of NPG, NPG/RGO ribbon and powder nanocomposites have a better catalytic activity for MOR than NPG. Adding GO in dealloying process could be one new method to obtain the NPG materials with the excellent catalytic activity.

Table 4 The corrosion potential $E_{\text {corr }}(\mathrm{V})$, anodic slope $\beta_{\mathrm{a}}\left(\mathrm{mV} \mathrm{dec} \mathrm{c}^{-1}\right)$, and exchange current density $j_{0}\left(\mathrm{~mA} \mathrm{~cm}^{-2}\right)$ obtained from Tafel curves of $\mathrm{PO}$ and $\mathrm{P} 1$ electrodes in alkaline and acid solutions, respectively

\begin{tabular}{lllrr}
\hline Solutions & Samples & $E_{\mathrm{corr}}(\mathrm{V})$ & $\beta_{\mathrm{a}}\left(\mathrm{mV} \mathrm{dec}^{-1}\right)$ & $j_{0}\left(\mathrm{~mA} \mathrm{~cm}^{-2}\right)$ \\
\hline $0.5 \mathrm{M} \mathrm{KOH}+$ 0.5 M methanol & P0 & -1.585 & 124.9 & 7.64 \\
& P1 & -1.834 & 78.2 & 5.53 \\
$0.5 \mathrm{M} \mathrm{H}_{2} \mathrm{SO}_{4}+0.5 \mathrm{M}$ methanol & P0 & -0.612 & 166.8 & 4.01 \\
& P1 & -0.684 & 90.4
\end{tabular}




\section{Conclusions}

(1) The nanoporous gold and reduced oxidized graphene (NPG/ RGO) nanocomposites in ribbon shape were successfully prepared by dealloying $\mathrm{Al}_{2} \mathrm{Au}_{1}$ ribbons in $10 \mathrm{wt} \% \mathrm{HCl}$ solution with various $\mathrm{GO}$ concentration $\left(C_{\mathrm{GO}}=0,50\right.$, and $\left.100 \mathrm{ppm}\right)$, which were labeled as S0, S1, and S2, respectively. The RGO nanosheets of S1 and S2 are anchored on the surface of NPG in a cicadas wing like shape.

(2) With increasing the $C_{\mathrm{GO}}$, the lattice constant $a_{0}$, and nanograin boundary density of $3 \mathrm{D}$ bicontinuous NPG and the thickness of RGO tend to increase. The catalytic activity of S1 for methanol electro-oxidation reaction (MOR) is the highest due to the optimized NPG structure and the role of conductive agent and buffer layer played by RGO.

(3) The NPG/RGO nanocomposites in powder shape were also successfully prepared by dealloying the $\mathrm{Al}_{2} \mathrm{Au}$ powders in $10 \mathrm{wt} \% \mathrm{HCl}$ solution with $C_{\mathrm{GO}}=0$ and $50 \mathrm{ppm}$ (labeled as P0 and P1). The catalytic activity for MOR of P1 is higher than P0 and has a marvelous structural stability after electrochemical tests. These results supply a new method for us to obtain the nanoporous gold with excellent catalytic activity through adding $\mathrm{GO}$ in dealloying process.

\section{Conflicts of interest}

There are no conflicts to declare.

\section{Acknowledgements}

The authors are grateful for financial support from National Key Research Program of China (Grant No. 2016YFB0300501), National Natural Science Foundation of China (No. 51471099, 51571132, and 51771103), and China Postdoctoral Science Foundation (No. 19B10601).

\section{References}

1 M. Valden, X. Lai and D. W. Goodman, Science, 1998, 281, 1647-1650.

2 M. Haruta, Nature, 2005, 437, 1098-1099.

3 H. Tsunoyama, H. Sakurai, Y. Negishi and T. Tsukuda, J. Am. Chem. Soc., 2005, 127, 9374-9375.

4 J. Luo, P. N. Njoki, Y. Lin, D. Mott, L. Y. Wang and C. J. Zhang, Langmuir, 2006, 22, 2892-2898.

5 A. Wittstock, B. Neumann, A. Schaefer, K. Dumbuya, C. Kübel, M. M. Biener, V. Zielasek, H.-P. Steinrück, J. M. Gottfried, J. Biener, A. Hamza and M. Bäumer, J. Phys. Chem. C, 2009, 113, 5593-5600.

6 A. Wittstock, J. Biener and M. Bäumer, Phys. Chem. Chem. Phys., 2010, 12, 12919-12930.

7 M. C. Daniel and D. Astruc, Chem. Rev., 2004, 104, 293-346. 8 Y. Tian and T. Tatsuma, J. Am. Chem. Soc., 2005, 127, 76327637.

9 Y. Ding and M. W. Chen, MRS Bull., 2009, 34, 569-576.

10 J. Biener, M. M. Biener, R. J. Madix and C. M. Friend, ACS Catal., 2015, 5, 6263-6270.
11 M. L. Personick, B. Zugic, M. M. Biener, J. Biener, R. J. Madix and C. M. Friend, ACS Catal., 2015, 5, 4237-4241.

12 Z. Borkowska, A. Tymosiak-Zielinska and G. Shul, Electrochim. Acta, 2004, 49, 1209-1220.

13 H. S. Liu, C. J. Song, L. Zhang, J. J. Zhang, H. J. Wang and D. P. Wilkinson, J. Power Sources, 2006, 155, 95-110.

14 R. K. Raman, A. K. Shukla, A. Gayen, M. S. Hegde, K. R. Priolkar, P. R. Sarode and S. Emura, J. Power Sources, 2006, 157, 45-55.

15 R. F. Wang, H. Wang, B. X. Wei, W. Wang and Z. Q. Lei, Int. J. Hydrogen Energy, 2010, 35, 10081-10086.

16 J. P. Liu, J. Q. Ye, C. W. Xu, S. P. Jiang and Y. X. Tong, J. Power Sources, 2008, 177, 67-70.

17 J. T. Zhang, P. P. Liu, H. Y. Ma and Y. Ding, J. Phys. Chem. C, 2007, 111, 10382-10388.

18 Z. Borkowska, A. Tymosiak-Zielinska and R. Nowakowski, Electrochim. Acta, 2004, 49, 2613-2621.

19 M. Avramov-Ivić, V. Jovanović, G. Vlajnić and J. Popić, J. Electroanal. Chem., 1997, 423, 119-124.

20 V. Z. A. Wittstock, J. Biener, C. M. Friend and M. Bäumer, Science, 2010, 327, 319-322.

21 T. Fujita, P. F. Guan, K. McKenna, X. Y. Lang, A. Hirata, L. Zhang, T. Tokunaga, S. Arai, Y. Yamamoto and N. Tanaka, Nat. Mater., 2012, 11, 775-780.

22 S. Liu, J. K. Feng, X. F. Bian, Y. T. Qian, J. Liu and H. Xu, Nano Energy, 2015, 13, 651-657.

23 S. Liu, J. K. Feng, X. F. Bian, J. Liu and H. Xu, Energy Environ. Sci., 2016, 9, 1229-1236.

24 H. Rösner, S. Parida, D. Kramer, C. A. Volkert and J. Weissmüller, Adv. Eng. Mater., 2007, 9, 535-541.

25 Y. Ding, Y. J. Kim and J. Erlebacher, Adv. Mater., 2004, 16, 1897-1900.

26 L. H. Qian and M. W. Chen, Appl. Phys. Lett., 2007, 91, 083105.

27 Z. H. Zhang, Y. Wang, Z. Qi, W. H. Zhang, J. Y. Qin and J. Frenzel, J. Phys. Chem. C, 2009, 113, 12629-12636.

28 H. Ji, X. G. Wang, C. C. Zhao, C. Zhang, J. L. Xu and Z. H. Zhang, CrystEngComm, 2011, 13, 2617-2628.

29 Z. H. Zhang, Y. Wang, Z. Qi, C. Somsen, X. G. Wang and C. C. Zhao, J. Mater. Chem., 2009, 19, 6042-6050.

30 L. V. Moskaleva, S. Rohe, A. Wittstock, V. Zielasek, T. Kluner, K. M. Neyman and M. Bäumer, Phys. Chem. Chem. Phys., 2011, 13, 4529-4539.

31 H. Xu, K. C. Shen, S. Liu, L.-C. Zhang, X. G. Wang, J. Y. Qin and W. M. Wang, J. Phys. Chem. C, 2016, 120, 25296-25305.

32 H. Xu, K. Shen, S. Liu, L.-C. Zhang, X. Wang, J. Qin and W. Wang, J. Phys. Chem. C, 2018, 122, 3371-3385.

33 M. J. McAllister, J.-L. Li, D. H. Adamson, H. C. Schniepp, A. A. Abdala, J. Liu, M. Herrera-Alonso, D. L. Milius, R. Car, R. K. Prud'homme and I. A. Aksay, Chem. Mater., 2007, 19, 4396-4404.

34 Y. Kopelevich and P. Esquinazi, Adv. Mater., 2007, 19, 45594563.

35 T. Schwamb, B. R. Burg, N. C. Schirmer and D. Poulikakos, Nanotechnology, 2009, 20, 405704. 
36 C. Gómez-Navarro, R. T. Weitz, A. M. Bittner, M. Scolari, A. Mews, M. Burghard and K. Kern, Nano Lett., 2007, 7, 3499-3503.

37 Y. B. Zhang, Y.-W. Tan, H. L. Stormer and P. Kim, Nature, 2005, 438, 201-204.

38 D. A. Dikin, S. Stankovich, E. J. Zimney, R. D. Piner, G. H. Dommett, G. Evmenenko, S. T. Nguyen and R. S. Ruoff, Nature, 2007, 448, 457-460.

39 S. Stankovich, D. A. Dikin, G. H. B. Dommett, K. M. Kohlhaas, E. J. Zimney, E. A. Stach, R. D. Piner, S. T. Nguyen and R. S. Ruoff, Nature, 2006, 442, 282-286.

40 F. Scarpa, S. Adhikari and A. Srikantha Phani, Nanotechnology, 2009, 20, 065709.

41 K. S. Novoselov, A. K. Geim, S. V. Morozov, D. Jiang, Y. Zhang, S. V. Dubonos, I. V. Grigorieva and A. A. Firsov, Science, 2004, 306, 666-669.

42 Y. Li, X. B. Fan, J. J. Qi, J. Y. Ji, S. L. Wang, G. L. Zhang and F. B. Zhang, Nano Res., 2010, 3, 429-437.

43 E. Yoo, T. Okata, T. Akita, M. Kohyama, J. Nakamura and I. Honma, Nano Lett., 2009, 9, 2255-2259.

44 X. Cui, C. Z. Zhang, R. Hao and Y. L. Hou, Nanoscale, 2011, 3, 2118-2126.

45 X. M. Chen, G. H. Wu, J. M. Chen, X. Chen, Z. X. Xie and X. R. Wang, J. Am. Chem. Soc., 2011, 133, 3693-3695.

46 P. Kundu, C. Nethravathi, P. A. Deshpande, M. Rajamathi, G. Madras and N. Ravishankar, Chem. Mater., 2011, 23, 2772-2780.

47 R. Muszynski, B. Seger and P. V. Kamat, J. Phys. Chem. C, 2008, 112, 5263-5266.

48 S. Liu, J. Q. Tian, L. Wang, H. L. Li, Y. W. Zhang and X. P. Sun, Macromolecules, 2010, 43, 10078-10083.

49 K. Jasuja and V. Berry, ACS Nano, 2009, 3, 2358-2366.

50 X. Y. Lang, P. F. Guan, L. Zhang, T. Fujita and M. W. Chen, Appl. Phys. Lett., 2010, 96, 073701.

51 J. Feng, Z. Zhang, L. Ci, W. Zhai, Q. Ai and S. Xiong, J. Power Sources, 2015, 287, 177-183.

52 J. Deng, D. Deng and X. Bao, Adv. Mater., 2017, 29, 1606967.

53 W. Zhai, Q. Ai, L. Chen, S. Wei, D. Li, L. Zhang, P. Si, J. Feng and L. Ci, Nano Res., 2017, 10, 4274-4283.

54 D. R. Dreyer, S. Park, C. W. Bielawski and R. S. Ruoff, Chem. Soc. Rev., 2010, 39, 228-240.

55 Y. Zhou, Materials Analysis and Testing Technology, Harbin Institute of Technology Press, Harbin, 2007.

56 F. K. Lotgering, J. Inorg. Nucl. Chem., 1959, 9, 113-123.

57 E. J. Schofield, B. Ingham, A. Turnbull, M. F. Toney and M. P. Ryan, Appl. Phys. Lett., 2008, 92, 043118.
58 X. Su, Q. Wu, J. Li, X. Xiao, A. Lott, W. Lu, B. W. Sheldon and J. Wu, Adv. Energy Mater., 2014, 4, 1300882.

59 M. Avramov-Ivić, V. Jovanović, G. Vlajnić and J. Popić, J. Electroanal. Chem., 1997, 423, 119-124.

60 G. Tremiliosi-Filho, E. R. Gonzalez, A. J. Motheo, E. M. Belgsir, J. M. Léger and C. Lamy, J. Electroanal. Chem., 1998, 444, 31-39.

61 A. Tymosiak-Zielińlska and Z. Borkowska, Electrochim. Acta, 2000, 45, 3105-3116.

62 K. A. Assiongbon and D. Roy, Surf. Sci., 2005, 594, 99-119.

63 S. N. Azizi, S. Ghasemi and F. Amiripour, Electrochim. Acta, 2014, 137, 395-403.

64 K. C. Shen, C. G. Jia, B. X. Cao, H. Xu, J. Wang, L.-C. Zhang, K. Kim and W. M. Wang, Electrochim. Acta, 2017, 256, 129138.

65 H. X. Luo, Z. J. Shi, N. Q. Li, Z. N. Gu and Q. K. Zhuang, Anal. Chem., 2001, 73, 915-920.

66 E. Telli, A. Döner and G. Kardaş, Electrochim. Acta, 2013, 107, 216-224.

67 A. J. Bard and L. R. Faulkner, Electrochemical Methods, J. Wiley, 2nd edn, New York, 2001.

68 N. Sattarahmady, H. Heli and F. Faramarzi, Talanta, 2010, 82, 1126-1135.

69 K. Shen, C. Jia, B. Cao, H. Xu, J. Wang, L. Zhang, K. Kim and W. Wang, Electrochim. Acta, 2017, 256, 129-138.

70 C. N. Cao, Corrosion Electrochemistry, Chemical Industry Press, Beijing, 1985.

$71 \mathrm{~J}$. Q. Zhang, Electrochemical Measurement Technology, Chemical Industry Press, Beijing, 2010.

72 X. Wang, G. Ma, F. Zhu, N. Lin, B. Tang and Z. Zhang, Electrochim. Acta, 2013, 114, 500-508.

73 H. Xu, S. Liu, L. Y. Guo, Y. J. Li, K. C. Shen, C. S. Guan and W. M. Wang, Int. J. Electrochem. Sci., 2015, 40, 4985-5000.

74 L. H. Jiang, G. Q. Sun, X. S. Zhao, Z. H. Zhou, S. Y. Yan, S. H. Tang, G. X. Wang, B. Zhou and Q. Xin, Electrochim. Acta, 2005, 50, 2371-2376.

75 A. Hamelin, J. Electroanal. Chem., 1996, 407, 1-11.

76 H. Xu, K. Shen, S. Liu, L.-c. Zhang, X. Wang, J. Qin and W. Wang, J. Phys. Chem. C, 2016, 120, 25296-25305.

77 H. N. Ok and A. H. Morrish, Phys. Rev. B: Condens. Matter Mater. Phys., 1981, 23, 2257-2261.

78 P. Liu, P. Guan, A. Hirata, L. Zhang, L. Chen, Y. Wen, Y. Ding, T. Fujita, J. Erlebacher and M. Chen, Adv. Mater., 2016, 28, 1753-1759. 